\title{
Los avances y problemas de la contratación con el Estado
}

\section{Progress and problems of contracting with the State}

\author{
VÍCTOR RAFAEL HERNÁNDEZ-MENDIBLE*
}

Resumen: Los contratos públicos han sido objeto de recientes reformas legales que han contribuido a consolidar que el hecho de que la administración pública, para satisfacer el interés general, realice la actividad administrativa con sujeción a la ley y al Derecho, y así ejerza las potestades atribuidas en el ordenamiento jurídico, lo que supone que en unos casos pueda actuar con aplicación preeminente del Derecho público y en otros casos actúe con aplicación preponderante del Derecho privado, con independencia del objeto del contrato (obras, bienes o servicios) y que este se encuentre en soporte físico, de papel, o en soporte electrónico, digital.

Palabras clave: Contratos - públicos - potestades administrativas - personas públicas

\begin{abstract}
Public procurement has been the subject of recent legal reforms that have helped to strengthen the Civil Service to meet the general conduct of administrative activity subject to the law and the law, exercising the powers conferred on the law and implying that in some cases can act pre-eminent application of Public Law and in other cases leading acts of private law enforcement, regardless of the contract (works, goods or services) and it is in support of physical, paper, or electronic, digital.
\end{abstract}

Key words: Contracts - publics - administrative powers - public figures

CONTENIDO: INTRODUCCIÓN.- I. LOS AVANCES EN LA CONTRATACIÓN CON EL ESTADO.- II. LOS PROBLEMAS EN LA CONTRATACIÓN CON EL ESTADO.III. CONSIDERACIONES FINALES.

\section{INTRODUCCIÓN}

Hace escasamente tres años, el Ejecutivo Nacional expidió el decreto con rango, valor y fuerza de Ley de Contrataciones Públicas ${ }^{1}$, que vino a llenar parcialmente un vacío en la regulación sobre los actos jurídicos contractuales de los órganos del Estado, en virtud que tal marco normativo de origen jurisprudencial ${ }^{2}$, se había construido durante medio siglo,

* Es doctor en Derecho y profesor en la Universidad Católica Andrés Bello y en la Universidad Monteávila de Venezuela, además de invitado en las maestrías de la Universidad Externado de Colombia y en la Universidad ESAN de Perú. www.hernandezmendible.com

1 Gaceta Oficial, № 38.895, 25 de marzo de 2008.

2 La Corte Federal y de Casación, sentencia de 5 de diciembre de 1944, admitió por primera vez la existencia de la categoría jurídica denominada contratos administrativos, justificada "en la doctrina de grandes autores modernos y no en preceptos legales especiales, en donde se establece que 
a través de la aplicación de diversas y dispersas disposiciones jurídicas que, combinadas con los principios generales del Derecho, habían contribuido a establecer el régimen de los contratos públicos, pero que no tenían un texto jurídico que permitiera brindar un régimen completo de la institución contractual.

En el corto tiempo, la Ley de Contrataciones Públicas ha sido objeto de dos reformas puntuales, la primera en el año $2009^{3}$ y la segunda en $2010^{4}$, sin que ellas hayan realmente servido para mejorar las carencias de las que adolecía la versión original.

Es importante señalar que la ley, al tener por objeto la regulación de los contratos públicos de prestación de servicios, adquisición de bienes y construcción de obras ${ }^{5}$ - lo que implícitamente deja por fuera a todos los demás contratos que no se circunscriban a estas categorías-, excluye expresamente de su ámbito de aplicación dos supuestos, en principio, subsumibles dentro de su ámbito ${ }^{6}$ : el primero consiste en la exclusión plena de la aplicación de la ley a los contratos que se formalizan en el ámbito de los acuerdos internacionales de cooperación entre Estados o que se ejecutan por empresas mixtas con motivo de tal cooperación? A su vez, el segundo consiste en la exclusión parcial de la aplicación de la ley, es decir, de los procedimientos administrativos de selección de contratistas previstos en la ley —no así del régimen sustantivo-, a determinados contratos que en principio se encuentran sometidos al ámbito de aplicación de la ley, estableciendo la posibilidad de que el Ejecutivo Nacional dicte, a través de un reglamento, las disposiciones que regularán la modalidad de selección en estos supuestos de exclusión, con sujeción a los principios que conforman el régimen legal contractual ${ }^{8}$.

En el año 2009 se expidió el reglamento de la Ley de Contrataciones Públicas ${ }^{9}$ y no se reguló el régimen especial de selección de contratistas para los contratos excluidos de ser adjudicados mediante los procedimientos administrativos de selección de contratistas, por lo que luego de tres años de dictada la ley, las autoridades públicas, cuando se encuentran en la necesidad de contratar, deben aplicar los procedimientos administrativos de selección de contratistas en los casos taxativamente contemplados en la ley, en tanto siguen teniendo vedado aplicar tales

no deben aplicarse por analogía a los contratos administrativos de suministros de provisiones ni a los trabajos públicos, las disposiciones de Derecho Privado sobre el contrato de venta ni sobre el arrendamiento o locación de cosas, se trata de la aplicación de conceptos jurídicos nuevos incompatibles con algunos preceptos del Derecho Privado y que por tanto, éstos [sic] deben ponerse a un lado".

3 Gaceta Oficial, № 39.165, 24 de abril de 2009.

4 Gaceta Oficial, № 39.503, 6 de septiembre de 2010.

5 Artículo 2 de la Ley de Contrataciones Públicas.

6 Hernández-Mendible, Víctor R. "Los contratos excluidos de la Ley de Contrataciones Públicas y la libertad de elección”. Revista Jurídica del Perú, № 93, Normas Legales, 2008, pp. 212-222, Lima.

7 Artículo 4 de la Ley de Contrataciones Públicas.

8 Artículo 5 de la Ley de Contrataciones Públicas.

9 Gaceta Oficial, № 39.181, 19 de mayo de 2009. 
procedimientos a aquellos contratos excluidos por la propia ley, lo que los conduce a seleccionar los contratistas conforme al principio de libertad de elección ${ }^{10}$.

La situación anteriormente descrita no ofrece una visión panorámica de los retos a los cuales se enfrentan los operadores jurídicos en materia de contratación pública, pues cabe añadir que la otra categoría de contratos públicos que presenta trascendencia en la actualidad es la de los contratos de concesión de infraestructuras y de servicios públicos, los cuales no se encuentran regulados en la citada Ley de Contrataciones Públicas.

Respecto a los contratos de concesión, el régimen jurídico resulta aún más complejo, porque existe un marco normativo nacional constituido por el decreto con rango, valor y fuerza de Ley de Promoción de la Inversión Privada bajo el Régimen de Concesiones ${ }^{11}$, que siempre deberá ser utilizado para otorgar las concesiones de infraestructuras y servicios públicos ${ }^{12}$, por el Ejecutivo Nacional o la administración pública nacional descentralizada funcionalmente.

En lo que respecta a las entidades político-territoriales que integran la federación, denominadas Estados ${ }^{13}$, puesto que estas tienen atribuido dentro del ámbito de sus competencias constitucionales dictar leyes estatales ${ }^{14}$, pueden establecer su propio régimen jurídico de concesiones de infraestructuras ${ }^{15}$ y servicios públicos ${ }^{16}$ de su competencia. De allí que el decreto-ley nacional de concesiones resulte de utilización discrecional para el Ejecutivo Estatal ${ }^{17}$, pues no se encuentra legalmente obligado a utilizarlo y, en caso de contar con su propia legislación, debe acudir a este únicamente de manera supletoria. Quedará solamente de aplicación principal y directa cuando el Estado carezca absolutamente de regulación propia en la materia y requiera utilizar la modalidad de contratación pública concesional, para realizar un negocio jurídico que persiga la satisfacción del interés general mediante esta figura.

Otro tanto sucede con los municipios, que constituyen las entidades político-territoriales primarias de la organización del Estado ${ }^{18}$ y que, al gozar de personalidad jurídica y autonomía reconocida en la

10 Hernández-Mendible, Víctor R. "El régimen jurídico del procedimiento de selección y del expediente administrativo de contratación". En Ley de contrataciones públicas. Segunda edición actualizada y aumentada. Caracas: Editorial Jurídica Venezolana, 2009, pp. 69-71.

11 Gaceta Oficial, № 5.394, 25 de octubre de 1999.

12 Hernández-Mendible, Víctor R. "Los contratos de obra pública, concesión de obra pública y concesión de servicio público en Venezuela". Revista de Derecho Público, 2007-1, 2007, pp. 343376, Buenos Aires.

13 Artículo 16 de la Constitución.

14 Artículo 162.1 de la Constitución.

15 Artículo 164.9 de la Constitución.

16 Artículo 164.8 de la Constitución.

17 Artículo 5 del decreto con rango, valor y fuerza de Ley de Promoción de la Inversión Privada bajo el Régimen de Concesiones.

18 Artículo 16 de la Constitución y 2 de la Ley Orgánica del Poder Público Municipal, publicada en Gaceta Oficial, № 6.015, de 28 de diciembre de 2010.

LOS AVANCES Y PROBLEMAS DE LA CONTRATACIÓN CON EL ESTADO

PROGRESS AND PROBLEMS OF CONTRACTING WITH THE STATE 
Constitución ${ }^{19}$, tienen atribuida la potestad para legislar en las materias de su propia competencia ${ }^{20}$, en armonía y desarrollo de la legislación nacional. En atención a ello, cabe destacar que los municipios no tienen la obligación legal de aplicar el decreto-ley nacional de concesiones, pues el propio texto jurídico los habilita para aplicar otras disposiciones con preferencia y porque la ley orgánica del poder público municipal dispone las reglas que deben contemplar las ordenanzas como leyes locales para regular las concesiones municipales y en especial las concesiones de servicios públicos ${ }^{21}$.

Así, corresponde analizar cuáles son los avances y dificultades que presenta la contratación con el Estado, teniendo presente que el panorama normativo se antoja muy casuístico respecto a algunas categorías contractuales, y sumamente escueto con respecto a otras.

Para una mayor claridad en la exposición de las ideas, dividiré el presente trabajo en los siguientes aspectos a saber: los avances en la contratación con el Estado (ii); los problemas en la contratación con el Estado (iii); y las consideraciones finales (iv).

\section{LOS AVANCES EN LA CONTRATACIÓN CON EL ESTADO}

La contratación pública constituye una de las manifestaciones de la actuación de la administración pública, que tiene por finalidad la satisfacción del interés general del que ella es vicaria y constituye una modalidad de administración y ejecución del presupuesto público, por lo que se requiere que dicha actuación sea ética, transparente, responsable, con rendición de cuentas y con sujeción a lo que disponga la ley y preceptúe el Derecho.

Es de aceptación común que en los contratos públicos no existe una relación de igualdad entre las partes ${ }^{22}$, por lo que aquello que fue calificado como cláusulas exorbitantes ${ }^{23}$ que se encontraban de manera expresa o implícita ${ }^{24}$ en los denominados contratos administrativos, no eran otra cosa que el reconocimiento de potestades a la administración pública ${ }^{25}$, no susceptible de encontrarse —o más correctamente aplicarse- en

19 Artículo 168 de la Constitución.

20 Artículo 4.5 de la Ley Orgánica del Poder Público Municipal.

21 Artículo 73 de la Ley Orgánica del Poder Público Municipal.

22 Tribunal Supremo de Justicia en Sala Constitucional, sentencia de 8 de diciembre de 2000.

23 La Procuraduría General de la República, en su doctrina, había establecido a comienzos de la década de los sesenta que "se entienden las cláusulas exorbitantes como aquellas que salen de la órbita del Derecho Común y colocan a la Administración, no solo en una situación de privilegio —que es lo usual- sino que, en virtud de las mismas, puede, incluso, la Administración sacrificarse en aras de un interés público y pactar condiciones tan desventajosas que serían inconcebibles en un particular que contrate". Doctrina de la Procuraduría General de la República, Caracas, 1963. p. 137.

24 Corte Suprema de Justicia en Sala Político Administrativa, de 22 de noviembre de 1990; de 9 de noviembre de 1983; de 27 de julio de 1995; y del Tribunal Supremo de Justicia en Sala Político Administrativa, sentencia del 5 de agosto de 2004.

25 Subero Mújica, Mauricio. La noción de contrato administrativo y la jurisprudencia en Venezuela. V. R. Hernández-Mendible (coordinador). Derecho administrativo iberoamericano. 100 autores en 
contratos privados y que se justificaban en la condición de vicaria del interés general atribuida a esta ${ }^{26}$.

No obstante, el punto que generaba mayor discusión consistía en reconocer estas potestades cuando no derivaban expresamente del contrato, pero que se consideraban como implícitas en el mismo en virtud de su naturaleza jurídica, aunque en contravención manifiesta del principio de legalidad, entendido en su sentido de vinculación positiva, que impide la existencia y el ejercicio de una competencia que no derive de una norma jurídica de las que integran el bloque de la legalidad ${ }^{27}$, lo que resultaba imposible al no existir una ley que regulase la contratación pública.

Si bien la jurisprudencia y doctrina científica no tuvieron mayor reparo

LOS AVANCES Y PROBLEMAS DE LA CONTRATACIÓN CON EL ESTADO

PROGRESS AND PROBLEMS OF CONTRACTING WITH THE STATE en aceptar inicialmente la existencia de las cláusulas exorbitantes, incluso las implícitas, luego se reconoció que las potestades atribuidas por ley a la administración pública, incluso cuando no estuviesen expresamente incorporadas en el texto del contrato, debían considerarse insertas en el mismo y resultan perfectamente ejecutables siempre que tuviesen su basamento en una norma legal ${ }^{28}$.

Es así como, primero en el decreto con rango, valor y fuerza de Ley de Promoción de la Inversión Privada bajo el Régimen de Concesiones en 1999 y luego con la expedición del decreto con rango, valor y fuerza de Ley de Contrataciones Públicas en 2008, se establecieron algunas de las potestades que, conforme al principio de legalidad, pueden ejercer las administraciones públicas en sus relaciones contractuales.

Son estas potestades administrativas expresamente establecidas en las leyes, uno de los mayores avances en la contratación con el Estado, al lograr la efectiva sujeción de la administración pública durante la ejecución de los contratos públicos, a la ley y al Derecho.

Seguidamente, se mencionarán las potestades establecidas en el ordenamiento jurídico según los tipos de contratos públicos.

homenaje al postgrado de Derecho Administrativo en la Universidad Católica Andrés Bello. Tomo 3. Caracas: Ediciones Paredes, 2007, pp. 2055-2056.

26 La Corte Suprema de Justicia en Sala Político Administrativa, en su sentencia del primero de abril de 1986, se pronuncia sobre las cláusulas exorbitantes en los siguientes términos: "[...] dentro de los criterios utilizados para conceptuar el contrato administrativo y distinguirlo de los contratos de derecho privado que celebra la Administración se encuentra la Teoría de las Cláusulas Exorbitantes, que como su nombre lo indica, alude a estipulaciones creadores de privilegios de la Administración que rompen el principio de igualdad de las partes en la contratación, de tal naturaleza que de figurar en un contrato de derecho privado estarían afectadas de nulidad e incluso incidirían en el mismo sentido sobre la totalidad del contrato. El motivo por el cual se incluyen y justifican dichas cláusulas radica en la necesidad de la Administración de ejercer su potestad de supremacía en una relación contractual específica para así tutelar mejor los intereses que le han sido asignados".

27 Linares, Aurilivi. "Los principios que rigen los procedimientos administrativos de selección de contratistas". En Ley de Contrataciones Públicas. Segunda edición actualizada y aumentada. Caracas: Editorial Jurídica Venezolana, 2009, pp. 133-135.

28 Tribunal Supremo de Justicia en Sala Político Administrativa, sentencia del 21 de abril de 2004. En la doctrina científica, véase José I. Hernández. "El contrato administrativo en la Ley de Contrataciones Públicas venezolana”. Ley de Contrataciones Públicas. Ob. cit., pp. 179-180. 


\section{I.1. La potestad de dirección y control}

La potestad de dirección y control durante la ejecución del contrato tiene como finalidad garantizar el efectivo y fiel cumplimiento de las obligaciones adquiridas por el contratista, para lo cual la administración contratante puede ejercer la supervisión, inspección y vigilancia de lo que se está realizando.

Esta potestad se manifiesta de manera fundamental a través de órdenes e instrucciones que la administración contratante dirige al contratista, relacionadas con la ejecución del contrato. Durante toda la ejecución del contrato, la administración contratante dispone de las potestades de inspección, vigilancia y control que sean necesarias para asegurar el cumplimiento del contrato y, en especial, para verificar el adecuado desempeño del contratista, así como comprobar la sujeción de la ejecución a las obligaciones pactadas en el contrato ${ }^{29}$.

En términos similares, se ha reconocido a la administración contratante la potestad de ejercer el control y la fiscalización de los contratos que suscriba en ocasión de adjudicaciones establecidas en la Ley de Contrataciones Públicas; deberán designar para ello los supervisores o ingenieros inspectores, de acuerdo a la naturaleza del contrato ${ }^{30}$.

\section{I.2. La potestad de interpretación unilateral}

La potestad de interpretación le ha sido atribuida a la administración contratante para ejercerla durante la ejecución del contrato en aquellos supuestos en que se planteen discrepancias entre las partes acerca de la interpretación o el alcance de algunas de las cláusulas contractuales que puedan afectar o incidir en la ejecución del contrato.

En caso de plantearse una diferencia, debe buscarse un arreglo amigable entre las partes y, de no producirse un acuerdo entre estas, la administración contratante tiene la posibilidad de interpretar las estipulaciones contractuales objeto de la discrepancia mediante un acto administrativo que deberá ser debidamente motivado ${ }^{31}$.

Los supuestos de procedencia de la potestad de interpretación son los siguientes:

a. que exista una discrepancia respecto a la interpretación de unas cláusulas de contrato entre las partes contratantes;

b. que, existiendo las distintas interpretaciones, no se haya producido un acuerdo amigable entre las partes;

29 Artículo 37 del decreto con rango, valor y fuerza de Ley de Promoción de la Inversión Privada bajo el Régimen de Concesiones.

30 Artículo 112 de la Ley de Contrataciones Públicas.

31 Artículo 38 del decreto con rango, valor y fuerza de Ley de Promoción de la Inversión Privada bajo el Régimen de Concesiones. 
c. que con la finalidad de lograr la ejecución sin interrupciones, demoras o de manera distinta a la que justificó la contratación, la autoridad administrativa dicte un acto administrativo debidamente motivado ${ }^{32}$;

d. que la interpretación se circunscriba a las cláusulas que generaron las diferencias entre las partes.

La razón que justifica la atribución de esta potestad es la necesidad de no suspensión o interrupción de la ejecución del contrato, en virtud del interés general presente en la contratación ${ }^{33}$.

\section{I.3. La potestad de modificación}

La potestad de modificación es aquella otorgada a la administración contratante para alterar o variar los contratos aumentando o disminuyendo el objeto de la ejecución, cambiando los planos y los bienes por adquirir, y suspendiendo o reprogramando la ejecución de los servicios dentro de ciertos límites establecidos en la norma ${ }^{34}$.

Esta potestad goza de reconocimiento expreso en los dos textos que regulan los contratos públicos a los que se ha hecho referencia en el presente trabajo. Así, con respecto a los contratos de concesión, una vez perfeccionado el contrato, la administración contratante podrá modificar, por razones de interés general y mediante acto administrativo debidamente motivado, las características del contrato de concesión de obras, bienes y servicios. En tales circunstancias, la administración contratante deberá compensar al contratista en caso de daños y perjuicios, mediante el otorgamiento de indemnizaciones ${ }^{35}$, en virtud del principio de responsabilidad administrativa, pilar fundamental del Estado de Derecho ${ }^{36}$.

En lo concerniente a la modificación de los contratos regulados por la Ley de Contrataciones Públicas, la administración contratante se encuentra facultada para introducir las modificaciones al contrato que estime necesarias, lo que podrá hacer antes o después de iniciada la ejecución del contrato y deberá notificar tales modificaciones al contratista ${ }^{37}$.

32 La Corte Federal y de Casación en Sala Federal, a través de su sentencia del 18 de enero de 1937, ha sostenido que la interpretación de un contrato debe regirse por el sentido de sus cláusulas, según la legislación vigente al momento de ejecutarse.

33 Araujo-Juárez, José. Derecho administrativo general. Actos y contratos administrativos. Caracas: Ediciones Paredes, 2011, p. 275.

34 La Corte Suprema de Justicia en Sala Político Administrativa, en su sentencia del 27 de enero de 1993, expresó: "La potestad de modificación unilateral, con el debido respeto al principio de la llamada ecuación o equilibrio económico, fue también colocada dentro de la posibilidad de la Administración de ejercer su supremacía en el negocio jurídico, por cuanto a través de ella la Administración puede cambiar, de acuerdo con sus propios intereses, alguno o algunos de los elementos del contrato, no solamente en sentido cuantitativo, sino también en ciertos casos, en sentido cualitativo".

35 Artículo 39 del decreto con rango, valor y fuerza de Ley de Promoción de la Inversión Privada bajo el Régimen de Concesiones.

36 Artículo 140 de la Constitución.

37 Artículo 106 de la Ley de Contrataciones Públicas.

LOS AVANCES Y PROBLEMAS DE LA CONTRATACIÓN CON EL ESTADO

PROGRESS AND PROBLEMS OF CONTRACTING WITH THE STATE 
Las razones que pueden constituirse en causa justificante de la modificación del contrato son las siguientes ${ }^{38}$ :

a. el incremento o reducción en la cantidad de las obras, bienes o servicios originalmente contratados ${ }^{39}$;

b. que surjan nuevas partidas o renglones a los contemplados en el contrato;

c. se modifique la fecha de entrega de los bienes, obras o servicios;

d. las variaciones en los montos previamente establecidos en el presupuesto original del contrato;

e. las establecidas en el artículo 140 del reglamento de la ley de contrataciones públicas.

Los principios que rigen el ejercicio de la potestad de modificación son:

a. En ningún caso puede alterarse la naturaleza del contrato; es decir, no puede utilizarse para novar el contrato.

b. Todas las modificaciones deben estar dirigidas a la satisfacción del interés general del que es vicaria la administración ${ }^{40}$.

c. Cualquier modificación debe realizarse mediante la producción de un acto administrativo, dictado con sujeción a la Ley Orgánica de Procedimientos Administrativos.

\section{I.4. La potestad de suspensión}

La potestad de suspensión consiste en la posibilidad que tiene la administración contratante de ordenar la paralización de la ejecución del contrato, como consecuencia del ejercicio de la potestad de modificación o como medida preventiva antes de ejercer la potestad de resolución del contrato.

Ello lleva a considerar que, cuando la potestad de resolución del contrato se ejerce temporalmente, es una potestad instrumental para garantizar la mejor satisfacción del interés general involucrado en el contrato; en tanto que, cuando se ejerce de manera definitiva, lleva a la extinción del contrato conforme al ordenamiento jurídico.

38 Artículo 108 de la Ley de Contrataciones Públicas.

39 La Corte Federal y de Casación en Sala Federal, en su sentencia del 5 de diciembre de 1944, sostuvo que: "En el contrato [...] la parte representada por la autoridad administrativa no está obligada inflexiblemente por la regla de derecho privado de la intangibilidad de los contratos; sin necesidad de acuerdo previo con la otra parte, tiene derecho de introducir modificaciones en el plan de la obra, en sus planos, en los medios de ejecución y en esta misma, aumentándola o disminuyéndola".

40 La Corte Federal y de Casación en Sala Federal, en su sentencia del 5 de diciembre de 1944, estableció que "sería perjudicial a los intereses colectivos, pues fácilmente se comprenden los perjuicios que habría si la Administración necesitare de acuerdos previos con el contratista para introducir modificaciones en contratos que por su naturaleza y finalidad deben estar en todo momento sometidos a rectificaciones y mejoras que el mismo interés público aconseja". 
La ley reconoce que la administración contratante tiene competencia para ordenar la suspensión temporal de trabajos de ejecución de obras por causas no imputables al contratista o por modificación de tales trabajos $^{41}$. Esta competencia se ejerce a través del ingeniero inspector que tendrá la facultad de "suspender la ejecución de partes de la obra, cuando éstas no se estén ejecutando conforme a los documentos y normas técnicas, planos y especificaciones de la misma" ${ }^{2}$.

El ejercicio de la potestad de suspensión da lugar a indemnización, en la medida en que ella afecte el equilibrio económico financiero del contrato.

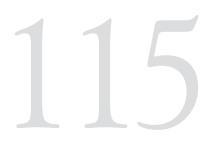

LOS AVANCES Y PROBLEMAS DE LA CONTRATACIÓN CON EL ESTADO

PROGRESS AND PROBLEMS OF CONTRACTING

\subsection{La potestad sancionatoria}

La potestad sancionatoria complementa la potestad de supervisión, inspección y control, y garantiza que esta pueda realizarse de manera eficiente, pues en caso de que la administración contratante indique una determinada actuación prevista en el contrato mediante órdenes o instrucciones y no logre que se realice, carecería de objeto la atribución de aquella potestad.

Esta potestad sancionatoria habilita a la administración contratante para que, durante la ejecución del contrato, disponga lo necesario para su efectivo cumplimiento y pueda imponer al contratista apercibimiento, sanciones establecidas en la ley, contempladas en el pliego de condiciones o en el texto del contrato para los casos de incumplimiento de este o de las resoluciones expedidas en ejercicio de la potestad de dirección y control, siempre que se tramite previamente el procedimiento administrativo legalmente establecido ${ }^{43}$-44.

Los principios que limitan el ejercicio de la potestad sancionatoria son los siguientes: legalidad ${ }^{45}$, tipicidad ${ }^{46}$, presunción de inocencia ${ }^{47}$, garantía del debido procedimiento ${ }^{48}$, garantía del derecho a la defensa ${ }^{49}$, garantía de la asistencia jurídica ${ }^{50}$, derecho a presentar pruebas ${ }^{51}$, derecho a no autoinculparse ${ }^{52}$, principio no dos veces lo mismo (non bis in idem) $)^{53}$,

41 Artículo 122.1 de la Ley de Contrataciones Públicas.

42 Artículo 115.5 de la Ley de Contrataciones Públicas.

43 Artículo 43 del decreto con rango, valor y fuerza de Ley de Promoción de la Inversión Privada bajo el Régimen de Concesiones.

44 Corte Suprema de Justicia en Sala Político Administrativa, sentencias de 7 de marzo de 1995 y de 11 de julio de 1996.

45 Artículo 49.6 de la Constitución.

46 Artículo 49.6 de la Constitución.

47 Artículo 49.2 de la Constitución.

48 Artículo 49 de la Constitución.

49 Artículo 49.1 de la Constitución.

50 Artículo 49.1 de la Constitución.

51 Artículo 49.1 de la Constitución.

52 Artículo 49.5 de la Constitución.

53 Artículo 49.7 de la Constitución. 
irretroactividad ${ }^{54}$, derecho al recurso $0^{55}$, derecho a la información oportuna y veraz ${ }^{56}$, derecho a la notificación de las resoluciones ${ }^{57}$, proporcionalidad, adecuación y racionalidad ${ }^{58}$, y prescripción ${ }^{59}$.

\section{I.6. La potestad de rescisión unilateral}

La potestad de rescisión unilateral implica que la administración contratante deje sin efecto un contrato o una obligación jurídica, deshaciendo un vínculo contractual válido.

Esta potestad puede ser ejercida tanto en caso de que haya mediado culpa del contratista ${ }^{60}$ como sin que este haya dado causa para ello ${ }^{61}$. Al respecto la jurisprudencia ha señalado que:

[...] aunque no conste este derecho en cláusula expresa del contrato, a saber, [se reconoce] el derecho que tiene toda autoridad administrativa que ha contratado una obra pública, destinada a un servicio público, de desistir de ella en cualquier tiempo aunque haya sido empezada. Si lo hace sin culpa del contratista deberá indemnizarle los perjuicios; pero si lo hace por incumplimiento de éste, el contratista lejos de ser acreedor por perjuicio deberá ser demandado para que los indemnice ${ }^{62}$.

Dicha potestad pública es irrenunciable y debe ser ejercida cuando se presenten las circunstancias contempladas en la norma jurídica atributiva de ella. Esto ha llevado a que la jurisprudencia considere que "en el campo de acción de los contratos administrativos, y aunque no conste en las cláusulas de la convención, la rescisión de ellos, cuando así lo demanden los intereses generales y públicos, es una facultad que la Administración no puede enajenar ni renunciar" ${ }^{\prime 3}$.

Tal potestad podrá ejecutarse siempre que se tramite previamente el debido procedimiento administrativo y se dé garantía del derecho a la defensa, tal como lo establece la Constitución y lo reconoce la jurisprudencia. En este sentido, se ha señalado que:

No basta que se produzca el incumplimiento del contratista para que la Administración declare, ipso facto, la caducidad o rescisión del contrato. El acto extintivo debe estar, en estos casos, precedido de un procedimiento administrativo, en el curso del cual resulte comprobado

54 Artículo 24 de la Constitución.

55 Artículo 49.1 de la Constitución.

56 Artículo 143 de la Constitución.

57 Artículo 143 de la Constitución.

58 Artículo 12 de la Ley Orgánica de Procedimientos Administrativos.

59 Artículo 70 de la Ley Orgánica de Procedimientos Administrativos.

60 Artículo 127 de la Ley de Contrataciones Públicas.

61 Artículo 190 de la Ley de Contrataciones Públicas.

62 Corte Federal y de Casación en Sala Federal, sentencia de 5 de diciembre de 1944.

63 Corte Federal y de Casación en Sala Federal, sentencia de 12 de noviembre de 1954. 
el incumplimiento y su imputabilidad al contratante. Todo ello como único medio capaz de garantizar el derecho a la defensa del particular cocontratante ${ }^{64}$.

En este mismo orden de ideas:

LOS AVANCES Y

[se] ha venido reiterando la potestad que tiene la Administración de rescindir unilateralmente un contrato (concesión) en aquellos casos de incumplimiento del contratante (concesionario), conforme lo establece, actualmente, el ordinal c) artículo 46 del Decreto con fuerza y rango de Ley Orgánica sobre Promoción de la Inversión Privada bajo el Régimen de Concesiones, publicado en la Gaceta Oficial № 5.394 Extraordinario de fecha 25 de octubre de 1999, caso en el cual, según afirma la jurisprudencia de esta Sala, existe la necesidad de seguir un procedimiento previo que garantice el derecho a la defensa y debido proceso ${ }^{65}$.

\section{I.7. La potestad preventiva}

La potestad administrativa preventiva únicamente habilita a la administración contratante para ejercerla, en el supuesto de que inicie el procedimiento administrativo con la finalidad de determinar el incumplimiento de la ejecución del contrato de obras.

El presupuesto para su ejercicio consiste en que se haya iniciado un procedimiento administrativo para determinar el presunto incumplimiento por parte del contratista, en los contratos de ejecución de obras, no siendo aplicable en caso de supuestos incumplimientos de los contratos de prestación de servicios o adquisición de bienes ${ }^{66}$.

Los motivos que justifican la adopción de medidas preventivas son dos supuestos: el primero, cuando la obra hubiere sido paralizada; y el segundo, cuando exista un riesgo inminente de su paralización ${ }^{67}$.

Es importante destacar que la paralización o amenaza de que ello ocurra, respecto a la ejecución del contrato de obras, se puede producir por causas no imputables al contratista. Si bien la ley no hace ninguna mención de ello, deberán aplicarse los principios de proporcionalidad y razonabilidad de las medidas administrativas preventivas.

Establece el legislador que el contratante podrá dictar y ejecutar como medidas administrativas preventivas: (a) la requisición de los bienes, equipos, instalaciones y maquinarias; y (b) el comiso de los materiales, destinados a la ejecución de la obra ${ }^{68}$. 
Esto lleva a señalar que la requisición consiste en el desapoderamiento por el Estado, mediante una orden administrativa, que traslada de manera coactiva y forzosa la posesión y uso de bienes muebles de los particulares, en principio, indeterminados y fungibles, o incluso se ha admitido la ocupación temporal de bienes inmuebles, cuando existan razones de necesidad temporal o de seguridad y defensa, de manera urgente y sin procedimiento previo alguno, situación que no se corresponde con las medidas preventivas administrativas.

Por su parte, el comiso constituye una sanción administrativa — sin perjuicio de la penal como consecuencia de un delito-, de carácter patrimonial que se le impone a una persona sobre bienes determinados, cuando ha realizado un acto ilícito, lo que produce como consecuencia la extinción de la propiedad del infractor sobre el bien y exige un procedimiento administrativo previo $\multimap$ o incluso penal- para determinar la ilicitud preestablecida en la ley, situación esta que tampoco se compadece con las medidas preventivas administrativas ${ }^{69}$.

Las medidas tienen por objeto dar continuidad a la ejecución de la obra y garantizar su culminación en el plazo establecido ${ }^{70}$.

Todos los bienes objeto de "requisición" o "comiso" bajo el acápite de medidas administrativas preventivas, quedarán a disposición de la administración contratante, mediante la ocupación temporal y posesión inmediata de los mismos ${ }^{71}$.

En el supuesto de que la resolución del procedimiento administrativo de rescisión le fuera favorable al contratista, éste podrá exigir a la administración contratante el reconocimiento de las inversiones que hubiere efectuado en la obra con relación a los materiales objeto del comiso y las maquinarias y equipos requisados ${ }^{72}$.

Las medidas administrativas preventivas permanecerán en vigencia hasta la recepción definitiva de la obra o hasta que se produzca su revocatoria por parte de la administración contratante ${ }^{73}$.

La redacción de la ley genera cierta confusión, pues cabe preguntarse iqué sucede en caso de que el procedimiento administrativo termine con una resolución que declare que no existe incumplimiento en la ejecución del contrato por el contratista, pero no se ha producido la recepción definitiva de la obra? En tal caso, el legislador no aclara debidamente si se mantendrían las medidas, hasta que se produzca su expresa 
revocatoria o un pronunciamiento jurisdiccional anulatorio, o si siempre se deberá esperar a la recepción definitiva de la obra.

No obstante, la respuesta a la anterior pregunta quizás puede deducirse de la atribución otorgada en la ley al funcionario competente, para que en cualquier momento del procedimiento administrativo, de oficio, pueda decretar la revocatoria, suspensión o modificación de las medidas administrativas preventivas que hubieren sido dictadas cuando, en su criterio, hayan desaparecido las condiciones que justificaron su procedencia; valga decir: que la obra no se encuentre paralizada o que haya desaparecido el riesgo inminente de su paralización ${ }^{74}$.

Como se puede apreciar, las medidas administrativas preventivas que la Ley de Contrataciones Públicas denomina "requisición" o "comiso" no se corresponden con las referidas figuras jurídicas; por el contrario, se asimilan más propiamente al aseguramiento de bienes dentro de un procedimiento administrativo, una especie de "embargo administrativo", que en principio persiguen garantizar las resultas de la tramitación de tal procedimiento, pero que, conforme se encuentran redactadas las normas, se pueden prolongar más allá de la tramitación de dicho procedimiento administrativo, hasta que se produzca la efectiva recepción de la obra.

\section{II.LOS PROBLEMAS EN LA CONTRATACIÓN CON EL ESTADO}

El tema de la contratación con el Estado puede conducir a la aparición de una multiplicidad de dificultades cuyo análisis excedería la extensión de este trabajo. No obstante, en este subepígrafe se van a mencionar algunos aspectos controversiales en dicha contratación. El primero, relacionado con el aspecto subjetivo: quiénes pueden contratar por el Estado; el segundo, vinculado con el aspecto material: cuál es el objeto que persigue el contrato; el tercero, atinente al régimen jurídico aplicable a los contratos; y, por último, la modalidad de procedimientos electrónicos de contratación.

\section{II.1. Los sujetos que pueden contratar por el Estado}

En virtud de lo establecido en el ordenamiento jurídico, las personas como sujetos titulares de derechos y con capacidad para asumir obligaciones, son quienes tienen la potestad de manifestar su voluntad de establecer, modificar o extinguir relaciones jurídicas, a través de la institución contractual. 
En el ámbito de la organización del Estado, no todos quienes actúan en su nombre tienen personalidad jurídica; es decir, no siempre quienes actúan en nombre y representación del Estado son personas morales a quienes se les pueden imputar derechos y exigir el cumplimiento de obligaciones, por lo que resulta necesario aclarar quiénes tienen la competencia para contratar en nombre del Estado.

$\mathrm{Al}$ respecto cabe señalar que la ley indica el ámbito de aplicación subjetivo: es decir, quiénes son los sujetos que se encuentran obligados a cumplir con las disposiciones contenidas en dicha ley.

Así, menciona a los "órganos y entes del Poder Público Nacional, Estatal y Municipal, Central y Descentralizado"75. Esta redacción ha sido cuestionada por la doctrina científica por dos razones. En primer lugar, porque confunde en la enumeración a los órganos que ejercen el poder público según lo establecido en la Constitución ${ }^{76}$ y a las personas jurídicas o morales, que son los auténticos titulares de derechos y obligaciones. En segundo término, porque no existe un poder público central y descentralizado, sino "una distribución territorial del poder público, como potestad estatal, en tres niveles de gobierno: nacional, estatal y municipal"'77, que es distinto a una administración pública central y descentralizada funcionalmente, que se encuentra sujeta a la regulación establecida en la ley orgánica de la administración pública ${ }^{78}$.

Esta mezcla de órganos que ejercen el poder público y personas jurídicas o morales públicas, lleva a efectuar algunas consideraciones para entender la imprecisión de la norma. $\mathrm{Al}$ respecto, cabe señalar que los órganos que ejercen el poder público nacional, según la concepción pentapartita de distribución del Poder establecida en la Constitución, son: Ejecutivo, Legislativo, Judicial, Ciudadano (integrado por la Contraloría General de la República, el Ministerio Público y la Defensoría del Pueblo) y Electoral ${ }^{79}$.

Todos ellos son órganos que ejercen el poder público en la entidad político territorial denominada República de Venezuela, la cual ostenta la personificación jurídica del Estado, tanto en el ámbito nacional, como internacionalmente ${ }^{80}$. En consecuencia, los órganos de la república asumen derechos y obligaciones en nombre de ella y, en consecuencia,

75 Artículo 3.1 de la Ley de Contrataciones Públicas.

76 Artículos 7 y 137 de la Constitución.

77 Brewer-Carías, Allan R. "Los contratos del Estado y las Ley de Contrataciones Públicas. Ámbito de aplicación". En Ley de Contrataciones Públicas. Ob. cit., pp. 40-41.

78 Gaceta Oficial, № 5.890, 31 de julio de 2008.

79 Artículo 136 de la Constitución.

80 La Corte Suprema de Justicia en Sala Político Administrativa, en su sentencia del 20 de enero de 1983, expresó que "desde que entró en vigencia la actual Constitución [23 de enero de 1961], en el campo jurídico venezolano tienen igual significación los términos de República y Estado, aunque esta última expresión será preferentemente empleada cuando se trate de distinguir las actividades públicas de las actividades privadas". 
los contratos que celebran son atribuibles a esta, como sujeto de derechos y obligaciones.

Los órganos que ejercen el poder público estatal, actúan en nombre de las entidades territoriales intermedias en la organización estatal y unidos integran la Federación de Estados ${ }^{81}$ — que tienen autonomía del Poder Federal y del Poder Municipal - y cada uno de ellos son personas jurídicas plenas, conforme a lo establecido en la Constitución ${ }^{82}$. En virtud de ello, sus órganos, el Ejecutivo Estatal, el Legislativo Estatal y el Contralor Estatal, actúan en nombre del respectivo Estado, a quien le son imputables los derechos y las obligaciones y, por ende, quien es el responsable de los contratos que celebren dichos órganos.

Los órganos que ejercen el poder público municipal, que constituye el Poder Local, constitucionalmente representan a las entidades territoriales menores que son los municipios, que también tienen atribuida autonomía y personalidad jurídica propia ${ }^{83}$. Estos actúan a través de sus órganos Ejecutivo Municipal, Legislativo Municipal y Contralor Municipal, pero en todo caso serán los municipios los sujetos a quienes se les imputan los derechos y las obligaciones, y serían, en consecuencia, quienes asumen las obligaciones, deberes y derechos derivados de los contratos que suscriben dichos órganos.

Todos los órganos antes mencionados ejecutan función administrativa a los efectos de la contratación pública que será atribuible a la república, el estado o el municipio respectivo.

Por otra parte, la administración pública existe en los tres niveles de división territorial: nacional, regional o local y puede ser central o descentralizada funcionalmente. La central no tiene personalidad jurídica, pues esta únicamente se encuentra atribuida a las entidades políticoterritoriales de las que ellas son parte. En cambio, la descentralizada funcionalmente se encuentra presente en cada uno de los mencionados niveles y se manifiesta a través de los institutos autónomos, las sociedades mercantiles, las asociaciones y sociedades civiles, las fundaciones, las cuales, aunque se consideran como integrantes de la administración pública, tienen atribuida personalidad jurídica propia y autonomía, en los términos establecidos en los actos jurídicos de creación, de conformidad con el ordenamiento jurídico.

En tal caso, estos entes descentralizados funcionalmente, al poseer personalidad jurídica, pueden ser titulares de derechos y adquirir obligaciones, de manera independiente a los órganos de las personas morales 
a los que se encuentran adscritos, en virtud de lo cual también pueden formalizar contratos públicos, con sujeción a la ley.

Aunque han sido considerados por la doctrina científica como integrantes de la administración pública descentralizada funcionalmente, se mencionan en el texto legal de manera separada de aquella, tanto al Banco Central de Venezuela como a las universidades impropiamente denominadas públicas, pues todas las universidades son públicas, lo que las diferencia es la modalidad de financiación y gestión, situación que permite distinguir entre universidades de financiación y gestión predominantemente pública, de las universidades de financiación y gestión predominantemente privada. Son justamente las universidades de financiación y gestión predominantemente pública, las que junto al Banco Central de Venezuela, se consideran personas jurídicas públicas o morales que deben cumplir con la Ley de Contrataciones Públicas.

\section{II.2. El objeto de los contratos}

La evolución jurisprudencial llegó a justificar las relaciones jurídicas contractuales de las personas públicas sometidas al Derecho administrativo, en una finalidad de servicio público ${ }^{84}$, una prestación de utilidad pública o interés general ${ }^{85}$, en un criterio o noción de servicio público ${ }^{86}$ que fue entendido en sentido amplio ${ }^{87}$.

La doctrina científica con sobrada razón ha criticado el empleo de los referidos conceptos jurídicos de manera indiscriminada e incluso como sinónimos, para justificar la presencia de los contratos administrativos como institución distinta de otras categorías contractuales. Así se destaca que "la jurisprudencia no se limita a hacer referencia concreta

84 La Corte Federal y de Casación en Sala Federal, en su sentencia del 5 de diciembre de 1944, expresaba que el concepto de contrato administrativo tiene su fundamento en que estos "interesan a los servicios públicos y los contratos de Derecho Privado, en los cuales, por los tiempos en que fue elaborada su preceptiva, no se dieron soluciones especiales y adecuadas a estos modernos contratos cuyo gran desenvolvimiento, nueva y minuciosa técnica no pudieron preverse".

85 La Corte Federal y de Casación en Sala Federal, en su sentencia del 12 de noviembre de 1954, sostuvo con respecto al contrato administrativo que "la especialidad de dichos contratos radica en el objeto y en el interés general que envuelven, y tal interés general puede ser el de la Nación o Estado, de las Provincias o de las Municipalidades".

86 La Corte Suprema de Justicia en Sala Político Administrativa, en su sentencia del 14 de junio de 1983 , señalaba, con respecto a la relevancia de la noción de servicio público en los contratos administrativos, que "indicadoras de que dichas cláusulas [exorbitantes] no hacen otra cosa que revelar con su existencia la noción - siempre presente en el contrato administrativo- de interés general o colectivo que el servicio público entraña. Si bien importante para identificarlo, ausentes de éste cláusulas exorbitantes recobra la noción de servicio público, presidida por la de interés general o colectivo en ella implícita, su plena y absoluta vigencia".

$87 \mathrm{La}$ Corte Suprema de Justicia en Sala Político Administrativa, en su sentencia del primero de abril de 1986, señaló que "el contrato trasluce asimismo, prima facie, que su objeto responde a la necesidad del desarrollo de actividades turísticas, las cuales caben dentro de la amplia noción de servicio público aceptada por nuestra doctrina y jurisprudencia como objeto posible de contratación administrativa". Respecto de la auténtica naturaleza de la actividad turística y su régimen jurídico diferenciado del servicio público, se recomienda Víctor R. Hernández-Mendible. "El Derecho administrativo y el Derecho del turismo". En Temas de Derecho constitucional y administrativo. Libro homenaje a Josefina Calcaño de Temeltas. Caracas: Funeda, 2010, pp. 653-692. 
a la noción de servicio público, sino que, por el contrario, suele emplear una serie de términos amplios y ambiguos" ${ }^{\prime 8}$, lo que conduce a que:

[...] estas expresiones y otras tantas empleadas en diversos fallos de la Sala Político Administrativa del Tribunal Supremo de Justicia, crean, todas ellas, una sensación de incertidumbre debido a su imprecisión. En efecto, se trata de expresiones muy amplias e inasibles: por ejemplo, debemos preguntarnos: ies admisible pensar, acaso, que la Administración pueda acudir a una contratación en defensa de un interés distinto del interés general?, ipuede la Administración perseguir —en sus contrataciones o en cualquier otra actividad - fines que no sean de utilidad pública?, e igualmente identifica otros conceptos que califica como aún más vagos e imprecisos, por una parte, la noción misma de servicio público y, por la otra, el vínculo entre el objeto del contrato y el servicio ${ }^{89}$.

Todo lo que permite concluir que la maleabilidad y elasticidad con que se emplean las nociones mencionadas para determinar la presencia de un contrato administrativo llevan a "la posibilidad de dar esta calificación a, prácticamente, cualquier contratación pública" ${ }^{9}$.

Sin duda, las preguntas formuladas por la doctrina científica tienen respuestas en el ordenamiento jurídico. Así se puede inferir que por mandato constitucional la administración pública en toda su actuación tiene el deber de hacerlo al servicio de los ciudadanos y perseguir la satisfacción del interés general, para lo cual debe ceñirse a los principios de eficiencia, eficacia, transparencia, honestidad, rendición de cuentas y responsabilidad con sujeción plena a la ley y al Derecho ${ }^{91}$.

Tal exigencia constitucional se concreta en el ámbito de la contratación pública, cuando la ley establece como su objeto regular la actividad administrativa de adquisición de bienes, prestación de servicios y ejecución de obras con la finalidad de preservar el patrimonio público, fortalecer la soberanía, desarrollar la capacidad productiva y asegurar la transparencia de las actuaciones de manera de coadyuvar al crecimiento sostenido y diversificado de la economía ${ }^{92}$.

Como se puede observar, más allá de que sea realmente posible lograr todos los objetivos mencionados en la ley a través de la contratación pública, la causa justificante de estos contratos se puede concretar en

88 Subero Mujica, Mauricio. "La noción de contrato administrativo y la jurisprudencia en Venezuela". En V. R. Hernández-Mendible (coordinador). Derecho administrativo iberoamericano. 100 autores en homenaje al postgrado de Derecho Administrativo en la Universidad Católica Andrés Bello. Tomo III. Caracas: Ediciones Paredes, 2007, p. 2051.

89 Subero Mujica, Mauricio. "La noción de contrato administrativo y la jurisprudencia en Venezuela". En V. R. Hernández-Mendible (coordinador). Derecho administrativo iberoamericano... Ob. cit., pp. 2051-2052.

90 lbíd., p. 2055.

91 Artículos 141 de la Constitución y 10 de la Ley Orgánica de la Administración Pública.

92 Artículo 1 de la Ley de Contrataciones Públicas.

LOS AVANCES Y PROBLEMAS DE LA CONTRATACIÓN CON EL ESTADO

PROGRESS AND PROBLEMS OF CONTRACTING WITH THE STATE 
la satisfacción de los intereses generales de los cuales la administración pública es vicaria, pues no se entiende que esta actúe impulsada por otros fines, que se sienta motivada a realizar la contratación, única y exclusivamente por el afán de lucro, por lícito que este sea.

\section{II.3. El régimen jurídico aplicable a los contratos}

El reconocimiento de la actividad contractual del Estado en principio no implicaba la existencia de un régimen jurídico especial, diferenciado o exorbitante a las disposiciones del Derecho civil.

De allí que uno de los temas que históricamente ha presentado una notable complejidad, es la justificación de la distinción entre los contratos administrativos y los contratos privados de la administración.

Las razones para ello son varias. En primer lugar, porque la Constitución no contenía, ni contiene referencia alguna a estas categorías contractuales y existió durante mucho tiempo una ausencia absoluta de legislación reguladora de la contratación pública. Al respecto, la doctrina científica señala que:

La noción de contrato administrativo, en ausencia de una ley general que los regule en Venezuela, sin duda, es una construcción doctrinal en cuya elaboración hemos contribuido en una forma u otra todos los que nos hemos ocupado de esta disciplina, al comentar la rica jurisprudencia de la Corte Suprema de Justicia, basada fundamentalmente en razones prácticas de orden adjetivo ${ }^{93}$.

En segundo lugar, porque la distinción nace de la asunción por la jurisprudencia de los criterios elaborados por la doctrina científica. En efecto, la Corte Federal y de Casación admitió por primera vez la existencia de la categoría jurídica denominada "contratos administrativos", justificada:

[...] en la doctrina de grandes autores modernos y no en preceptos legales especiales, en donde se establece que no deben aplicarse por analogía a los contratos administrativos de suministros de provisiones ni a los trabajos públicos, las disposiciones de Derecho Privado sobre el contrato de venta ni sobre el arrendamiento o locación de cosas, se trata de la aplicación de conceptos jurídicos nuevos incompatibles con algunos preceptos del Derecho Privado y que por tanto, éstos deben ponerse a un lado ${ }^{94}$.

93 Brewer-Carías, Allan R. "Nuevas consideraciones sobre el régimen jurídico de los contratos del Estado en Venezuela". En Los contratos administrativos. Contratos del Estado. Tomo I. Caracas: Funeda, 2006, p. 464.

94 Corte Federal y de Casación en Sala Federal, sentencia del 5 de diciembre de 1944. 
En tercer lugar, ello se debe a que la legislación de la zaga de los criterios doctrinales y jurisprudenciales no incorpora una noción o algunos criterios que permitan al operador jurídico efectuar la aludida distinción, lo que mantiene la incertidumbre sobre la categorización de los contratos que celebra la administración pública. Ha sido la jurisprudencia del orden jurisdiccional contencioso administrativo la que ha venido indicando casuísticamente cuándo se trata de una u otra categoría, entre otras razones por motivos de competencia procesal para determinar a qué orden jurisdiccional le corresponde conocer de los conflictos derivados de tales contratos.

En cuarto lugar, hay que tener presente que el acrítico reconocimiento a los contratos administrativos por su régimen preponderante de Derecho público, diferentes a los denominados contratos privados de la administración, sujetos a un régimen preeminente de Derecho privado, podría tener alguna justificación en lugares donde se ha reconocido la doble personalidad jurídica del Estado, pero carece de sustento en el ordenamiento jurídico venezolano, porque la personificación jurídica del Estado, tanto nacional como internacionalmente, es ejercida por la República de Venezuela como sujeto con competencia y capacidad para ser titular de derechos y asumir obligaciones.

De allí que el tercer problema que se ha planteado, al intentar la diferenciación de las dos categorías contractuales en virtud del régimen jurídico aplicable, es insostenible, porque por mandato constitucional la administración pública debe actuar con plena sujeción a la ley y al Derecho, lo que supone que su actividad contractual se encuentra sometida tanto a las disposiciones de Derecho público (Constitución, principios generales del Derecho, tratados internacionales, leyes y reglamentos nacionales) como de Derecho privado (Código Civil, Código de Comercio y otras disposiciones de similar naturaleza). Sucede que, conforme con el ordenamiento jurídico y la naturaleza del contrato, en algunos prevalecen disposiciones de Derecho público y en otros prevalecen disposiciones de Derecho privado.

\section{I.4. La actual tipificación de los contratos}

Lo expuesto anteriormente ha dado origen a un interesante debate doctrinal sobre la denominación de los contratos, en el sentido de ver cuál es la expresión más acertada: contratos del Estado, contratos de la administración, contratos del poder público, contratos administrativos o contratos públicos ${ }^{95}$. 
En tal sentido, debe señalarse que el legislador al expedir la ley ha apostado por la denominación de contratación pública y aunque tuvo el acierto de compilar con rango positivo los principios y las reglas que se habían venido construyendo de manera dispersa por la legislación, la doctrina científica y la jurisprudencia al desarrollar la institución de los contratos administrativos, no puede omitirse mencionar que este texto jurídico no regula toda la actividad contractual que podría considerarse comprendida en la expresión "contratos públicos"

Así, más allá de la expresión semántica, la Ley de Contrataciones Públicas ha venido a establecer un régimen general a los contratos que celebran las personas jurídicas o morales sometidas a su ámbito de aplicación, tanto en el marco precontractual, como en el contractual y poscontractual, con las excepciones derivadas del ordenamiento jurídico ${ }^{97}$ y que asume para tales contratos, muchos de los aspectos contemplados en el régimen jurídico de los contratos de concesión, regulados en el decreto con rango, fuerza y valor de Ley de Promoción de la Inversión Privada bajo el Régimen de Concesiones.

\section{II.5. Los procedimientos administrativos electrónicos de contratación}

El régimen de la contratación pública contiene algunas disposiciones reguladoras de los procedimientos administrativos de selección de contratistas que han sido objeto de varias reformas en la última década ${ }^{98} \mathrm{y}$ que regulan la selección de contratistas, mediante el uso de las nuevas tecnologías con que cuenta la administración pública ${ }^{99}$.

Sin embargo, a pesar de la buena intención subyacente en estas disposiciones, el asunto se torna más complejo, porque la administración electrónica (e-Administration) ${ }^{100}$, administración en línea (on line

96 Brewer-Carías, Allan R. "Los contratos del Estado...". Ob. cit., 10.

97 Hernández-Mendible, Víctor R. "Los contratos excluidos de la Ley de Contrataciones Públicas...". Óp. cit., pp. 212-222.

98 La Ley de Licitaciones, publicada en Gaceta Oficial, № 34.528, del 10 de agosto de 1990, fue reformada por el decreto con rango y fuerza de Ley de Licitaciones, publicado en Gaceta Oficial, № 5.386, del 11 de octubre de 1999, posteriormente reformado por el decreto con rango y fuerza de Ley de Licitaciones, publicado en Gaceta Oficial, № 37.097, del 11 de diciembre de 2000, modificado por el decreto con rango y fuerza de Ley de Licitaciones, publicado en Gaceta Oficial, № 5.556, del 13 de noviembre de 2001; luego fue derogada por el decreto con rango, valor y fuerza de Ley de Contrataciones Públicas, publicado en Gaceta Oficial, № 5.877, del 14 de marzo de 2008, reimpresa por error material en Gaceta Oficial, № 38.895, del 25 de marzo de 2008; reformada por la Ley de Contrataciones Públicas, publicada en Gaceta Oficial, № 39.165, del 24 de abril de 2009, posteriormente reformada en Gaceta Oficial, № 39.503, del 6 de septiembre de 2010, así como complementada por el Reglamento de la Ley de Contrataciones Públicas, publicado en Gaceta Oficial, № 39.181, del 19 de mayo de 2009.

99 Artículos 60, 79 al 81 de la Ley de Contrataciones Públicas y 120 al 122 del Reglamento de la Ley de Contrataciones Públicas.

100 Ernesto Jinesta Lobo sostiene que "las administraciones públicas electrónicas son aquellas que usan de manera extensiva e intensiva las tecnologías de la información y la comunicación en su organización, funciones o competencias y relaciones internas y externas, con los fines de racionalizar el gasto público, mejorar la calidad de los servicios públicos, obtener mayores grados 
Administration $)^{101}$ o gobierno electrónico (e-Government $)^{102,103}$, no cuenta con el marco jurídico integral que permita el desarrollo de los procedimientos administrativos electrónicos, en línea u on line.

Ello exige la implementación de una plataforma tecnológica neutra y abierta con los protocolos adecuados para garantizar la accesibilidad de las personas; la seguridad del sistema — a prueba de intrusos-; la calidad en el acceso, el envío, la transmisión y la recepción de documentos, información, datos de manera fidedigna; la asequibilidad que permita a todos poder sufragar el costo de acceso y satisfacer sus necesidades de interacción; la disponibilidad que implique la oportunidad de comunicación, sin restricciones de tiempo, lugar o sin que implique excluir a las personas que se encuentren en situaciones especiales; así como la interoperabilidad según los estándares técnicos determinados por la autoridad competente, lo cual permita la conexión a través de los equipos, las infraestructuras y las tecnologías, que actualmente existen en la Sociedad de la Información, el Conocimiento y la Innovación.

En el caso del procedimiento electrónico de selección de contratistas, los documentos y las actuaciones no se registran en soporte de papel, sino en soporte magnético o digital, por lo que el expediente también debe ser electrónico y las decisiones que ponen fin al procedimiento deben expedirse en el mismo soporte y estar suscritas a través de la firma electrónica.

Este proceso de implementación de la administración electrónica, en línea o gobierno electrónico constituye uno de los mayores retos para avanzar en la modalidad de la contratación electrónica, que hasta el presente encuentra como principal dificultad, las carencias en la implementación y aplicación de las tecnologías de la información y las comunicaciones en la gestión pública administrativa.

de eficiencia y eficacia, transparencia, y participación ciudadana y facilitar la rendición de cuentas y la evaluación del desempeño". En "Administraciones públicas electrónicas: retos y desafíos para su regulación en Iberoamérica”. V. R. Hernández-Mendible (coordinador). Desafíos del Derecho administrativo contemporáneo. Conmemoración Internacional de Centenario de la Cátedra de Derecho Administrativo en Venezuela. Tomo I. Caracas: Ediciones Paredes, 2009, pp. 174-175.

101 También se consideran sinónimos los siguientes: ciber administración, administración virtual, administración digital o tele administración. Carlos E. Delpiazzo. "Hacia dónde va el Derecho administrativo". En Carlos Mario Molina y Libardo Rodríguez R. (coordinadores). El Derecho público en Iberoamérica. Libro homenaje al profesor Jaime Vidal Perdomo. Tomo I. Bogotá: Universidad de Medellín-Temis, 2010, p. 392.

102 La Carta Iberoamericana de Gobierno Electrónico de Pucón, Chile, del primero de junio de 2007, aprobada en la IX Conferencia Iberoamericana de Ministros de Administración Pública y Reforma del Estado, párrafo 3, dispone que "se entienden las expresiones de 'Gobierno Electrónico' y de 'Administración Electrónica' como sinónimas, ambas consideradas como el uso de las TIC en los órganos de la Administración para mejorar la información y los servicios ofrecidos a los ciudadanos, orientar la eficacia y eficiencia de la gestión pública e incrementar sustantivamente la transparencia del sector público y la participación de los ciudadanos. Todo ello, sin perjuicio de las denominaciones establecidas en las legislaciones nacionales".

103 En la doctrina científica, la expresión gobierno electrónico se considera más amplia, pues comprende tanto la administración electrónica como los servicios que requieren los ciudadanos para participar en la toma de decisiones públicas, en la democracia electrónica. Carlos E. Delpiazzo. Ob. cit., p. 392. 


\section{CONSIDERACIONES FINALES}

Al efectuar un balance de la contratación con el Estado, se pueden advertir notables avances desde la perspectiva formal, al haberse normado en la Ley de Contrataciones Públicas, aspectos del régimen jurídico, económico-financiero e incluso técnicos, que carecían del debido soporte legislativo.

Sin duda, que actualmente existe mayor fundamento para sostener que la actividad administrativa precontractual (procedimientos administrativos de selección de contratistas), contractual (régimen jurídico de las distintas categorías de contratos y de las reglas de ejecución), poscontractual (marco legal de las sanciones, garantías y responsabilidades), se encuentra sujeta a la ley y el Derecho, es decir, que la administración pública en su actividad administrativa contractual guarda una mayor sujeción al principio de legalidad.

Desde la perspectiva técnica, se siguen padeciendo las carencias de una inadecuada regulación del gobierno electrónico o administración electrónica, lo que redunda en que las normas que podrían ser útiles para brindar más transparencia, garantizar mayor publicidad, concurrencia e igualdad, no se emplean porque no transmiten la confianza, seguridad y no garantizan la reserva de la información, circunstancias estas que no motivan a los convocantes a utilizar los procedimientos electrónicos de selección de contratistas; ni a los candidatos a participar y manifestar su voluntad, a fiarse de ellos y en consecuencia a responder a un eventual llamado realizado a través de las nuevas tecnologías.

Sin duda que aquí hay mucho camino por recorrer, que debe iniciarse de manera inmediata, para comenzar las reformas de tercera generación en la organización administrativa y los procedimientos que ellas se encuentran llamadas a implementar.

Las futuras reformas en la legislación de la contratación pública deben considerar tanto la transformación institucional del Estado constitucional y democrático de Derecho (del modelo prestacional al modelo de garantía de prestaciones) ${ }^{104}$, como el nivel de progreso tecnológico alcanzado por la Sociedad de la Información, el Conocimiento y la Innovación, que tiene como reto favorecer y facilitar el complejo de relaciones e informaciones que se generan entre las distintas administraciones públicas y las personas para contribuir de manera más eficaz a la satisfacción del interés general.

Si de algo puede hacer gala el ordenamiento jurídico venezolano, es de contar con un amplio régimen de controles en los supuestos de 
incumplimiento y violación de la legislación de contratación pública, que comprende ámbitos como el penal, administrativo, ético-económico, fiscal-presupuestario y contencioso-administrativo.

Sin embargo, tales controles no son suficientes, si no existe una ética respecto a la cosa pública y una auténtica conciencia cívica de los derechos y obligaciones que les corresponde a las personas frente a la administración pública, entre las que sobresalen el derecho a solicitar la rendición de cuentas, a que la gestión sea transparente y responsable, en fin, al derecho fundamental al buen gobierno y la buena administración ${ }^{105}$.

LOS AVANCES Y PROBLEMAS DE LA CONTRATACIÓN CON EL ESTADO PROGRESS AND PROBLEMS OF CONTRACTING WITH THE STATE 